\title{
Feeding the Nation
}

\section{A New Drying Process that Promises an Economic Revolution}

By R. G. Skerrett

WITH good reason, the world has part of the past two years how Germany has been able to feed her people in spite of the blockade maintained by her foes. Unquestionably; a notable part of her selfufficiency has been due to the widespread adoption of drying processes to preserve yegetables, fruits, and grains that might atherwise have been sacrificed through deterioration or decay. The dehydrating deterioration or decay. T. to convert these perishable products into foodstuffs that could be kept for many months without much loss in their nutritive properties. How extensive this industry has been for some years back can be gathere from the fact that just about drying establishments in the Fatherland, and these have been added to greatly since the outbreak of hostilities. Latterly, the German authorities have placed evaporating plants in all of the good-sized cities, and these have served to take care of temporary surplus of farm products, thus conserving, for the days of shortage, fruits that otherwise would have gone to waste.

A conspicuos economy has been effected in Germany through the drying of potato tops and beet tops for fodder. Prior to the desiccating of these leaves it wa the practice to store in silos quite two thirds of the beet tops, and because of unavoidable fermentation a very considerable part was spoiled. The drying treatment has eliminated this wastage, and has made it possible for the Teutons to maintain their livestock in an extremcly economical manner while fattening them to the desired degree for the market.

The German process for the preservation of vegetables has consisted in partly boiling them first to arrest certain organic tures cause a further radical alteration in physical appearance and chemical properties. To make them fit for the table, these desiccated vegetables require recooking, and, while unquestionably nutritive, they are not overpalatable no do their flavors closely resemble those of the fresh growths. Even so, the Germans were admittedly masters of this art until a year or two ago, when a rival American process was perfected.

The essential features of the American process, which has been patented and is in operation at three plants in the United States, consist in using heated air at temperatures far below those employed abroad and in insuring a thorough circulation of the air currents so as to reach eyery - particle of the fruits or vegetables undergoing desiccation. Consequently, the final yield of the drying apparatus is quite different from fimilar product treated by the German systems. To begin with, by the German systems. To begin with, the moisture is extracted so that the
residual water is well inside of 12 per cent and the desiccation does not injure the cellular membranes of the vegetable matter. The evaporation-depending upon the original water content of the vegetable or fruit-is accomplished within the remarkably short period of from two and one half to five hours. This is in notable contrast to the six and eight hours, and even much longer, required generally by other systems in which the removal of the water content ranges commonly well above twenty per cent. As a consequence, the vegetables and rits dried by this Amerkable degree their fresh taste and full flavor when prepared for the table; and because their cellular structure is uninjured they reacquire a normal appearance in a short while after being soaked in water.

It is authoritatively stated by the United States Department of Agriculture that quite fifty per cent of the vegetables and fruits grown here never reach the consumer's table; and it is equally certain that the major part of the produce so sacrificed does not leave the farm or orchard. This is because of : difficulties: of : transportation and the state of the' market, combined with the fact that only the very best of the fruits or vegetables will pass final inspection or or vegetables will pass final inspection or
lend themselves to profitable shipping.

marketed at a price welı below that of the so-called fresh products to be had only at certain seasons of the year.

The economic aspect of this matter is twofold. First, the farmer will no longer be hemmed in by local markets; his produce, when dried at nearby or conveniently located plants, can be cheaply delivered as demand dictates to any point in the United States or to foreign countries. Then, too, these dried products will be a great deal lighter than the fresh fruits or vegetables, and therefore, will take up less space than in their original form. This will lower proportionately the charges for transportation and storage. A large truck load of mixed vegetables can be dried by this process so that they will weigh but a hundred pounds and fill only a single barrel. Soup vegetables of this sort and weighing but one pound will make enough soup to satisfy sixty adults. For exploring parties, for large forces of workmen engaged far from a basc of supply, and for naval and military operations, this method of preserving foodstuffs promises to be

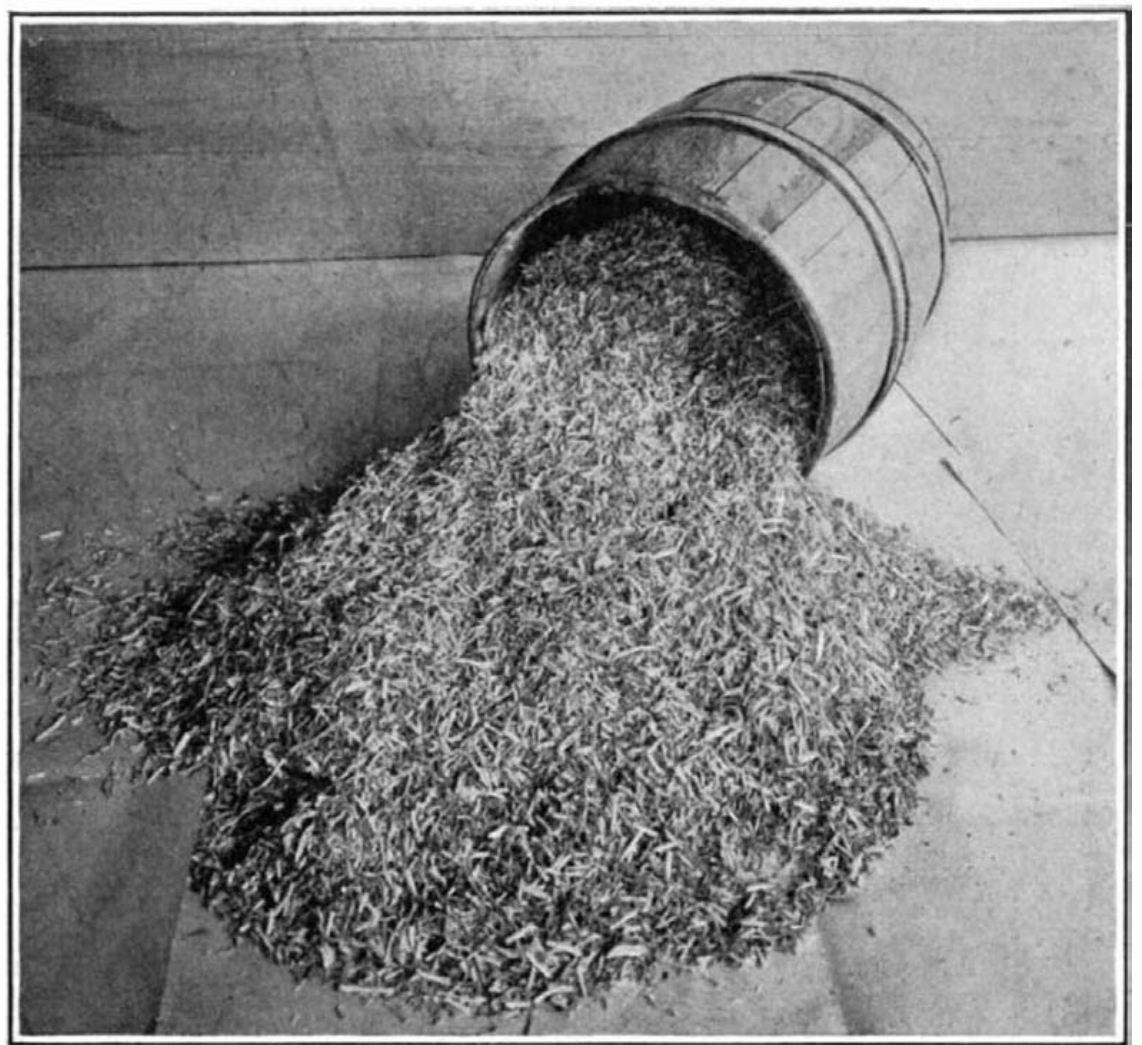

This barrel of dried stuff represents thirty barrels of green vegetables, and will make soup for 6,000 men

Nevertheless, by far the greater part of those product that do not leave the farm could be saved and made

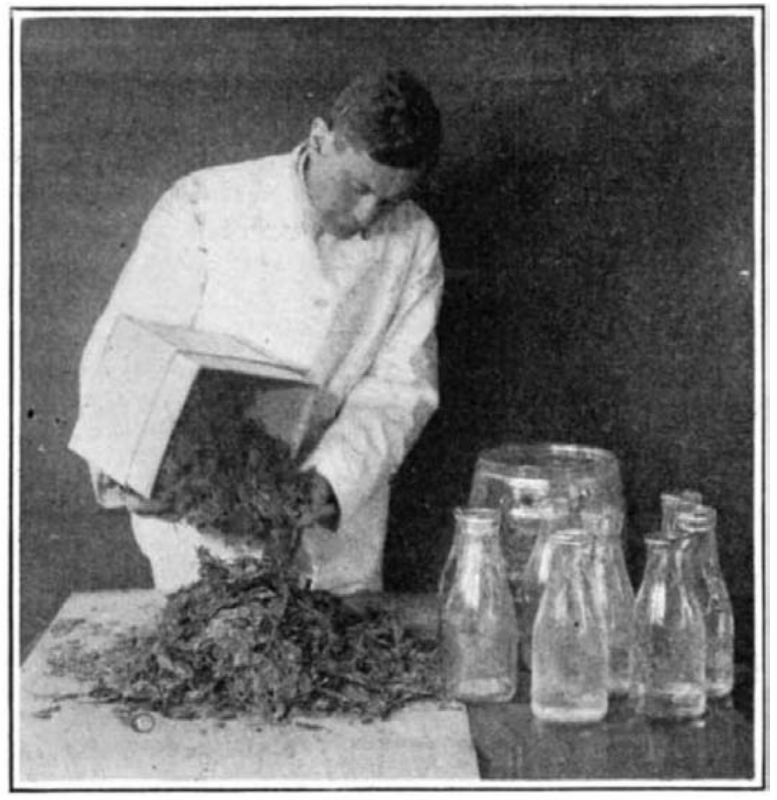

The bucket and milk bottles contain the water extracted from this box of vegetables

shows that the yields of farm and orchard can be conserved so as to keep well nigh indefinitely, and can be independent, if need be, of outside sources the sugar beet can be grown here far more extensively than it is possible for us to cultivate sugar within our continental limits. There is cheer for the northern districts of the country, farmers confidently count upon realizing $\$ 30$ per acre of sugar beets, while in California the return is in the neighborhood of $\$ 40$ and more.

The growing of sugar beets heretofore has been restricted to somewhat narrow zones immediately contiguous to the factories. Wagon hauling is not practicable or profitable beyond a distance of ten miles, and transportation charges limit rail carriage to an extreme radius of hundred miles from a refinery. Next, the so-called "campaign" or harvesting period does not extend beyond three months, and within this relatively short interval the sugar beets must be gathered and delivered directly to the factories. Even so, there are many practical difficulties that entai losses.

To begin with, the farmer naturally wants to harvest his product when his beets are biggest and the crop heaviest. The refiner, on the other hand, wants each contributing farmer's harvest delivered separately or at specified intervals, so that the regular daily tonnage to be handled wil just fit in with the factory's capacity. This ideal arrangement is well nigh impossible -under prevailing conditions, and, therefore, in order to take care of momentary overload, silos are sometimes installed to hold the excess beets for a while. There (Concluded on pape 268) 


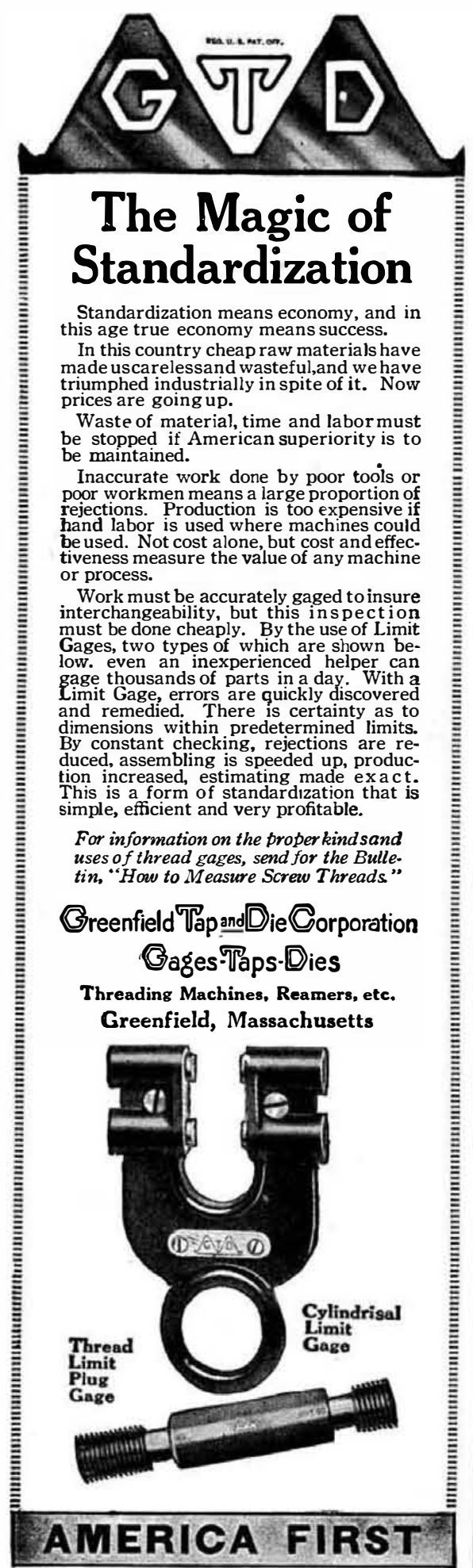

The War, the Reindeer, and the Aurochs

In short, in the north of Sweden, as in all countries when pastoral and agricultural industries are in contact there is a constant and bitter conflict between herdsmen and farmers, and the question has become Gordian knot for the authorities.

"In the interest of colonization, it is herds in to reduce the numbers of the this radical measure has been deferred for fear of causing discontent among a part of the population."

This is why the government is delighted to meet the demands of the German provisioners. In Norbotten, where the dinance prescribes that bitter, the royal or20,000 deer whose exportation is authorized must be comprised entirely of the "forest reindeer," which are those belonging to the "foresters." Since it is these which commit most of the depredations in the clear-
ings the farmers are highly pleased. On the other hand the Lapps are enchanted at selling their herds for prices hitherto undreamed, as high as 1.4 francs per kilogram $(28$ cents). Complementary ordinances provide that the herds thus depleted may not be restored to their former size, as also that 'sedentary' proprietors (in
Norbotten) must have disposed of thei herds within the next ten years. "Thus, within a near future these cerridae will be expelled from the whole forest zone of Swedish Lapland, $i$. e., from the largest part of the territory; only the mountain
zone will remain open to them. This restriction will very certainly entail a considerable diminution in the numbers of the Lapps."

The writer closes his article with a few paragraphs concerning the aurochs, saying that only three small groups of this surtwo in Russia and one on the northern slope of the Caucasus, and he considers the former doomed. "The principal herd of these bisons in Lithuania has its home in and Brest-Litovsk, where the fighting has been particularly lively; the second, much smaller, is in Volhynie . . . where the war has raged with equal violence.
These animals have survived hitherto only by grace of the safeguards with which they were surrounded by their noble proprietors. treated like the pheasants in the woods near Paris."

Feeding the Natior

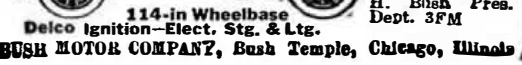

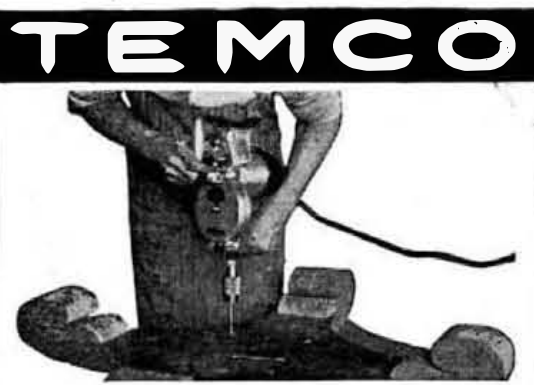

IT DRILLS-DRIVES SCREWS TAPS THREADS - GRINDS VALVES SHARPENS TOOLS

The Temco Portable Electric Tool has so mally
uses that it is almost a necessity in every factory
and machine shop.

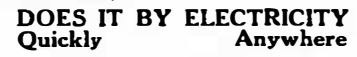

It's a veritable machine shop in itself. Can be
worked in any location about the factory ore ven
carried in a mechanic's kit for outside jobs. Does away with tiring hand work and gets
at work that the r.xed machine tool can't touch

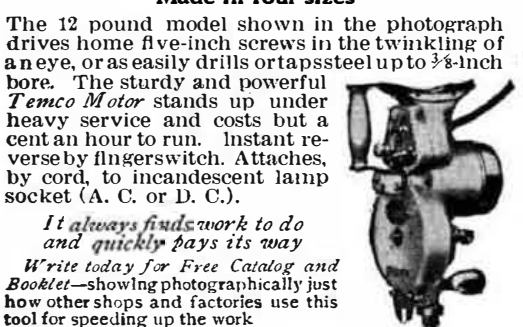

THE TEMCO ELECTRIC MOTOR COMPANY 1403 Sugar Street, Leipsic, Ohio is an inevitable loss in the silos owing to fermentation beets.

A factory capable of handling a thousand tons of beets a day represents a plant outlay of quite a million dollars. For nine months of the year this establishment is
idle, and all because beets can only be supplied to it for a maximum period of a hundred days annually. Even so, the beet sugar production of 1916 - measured
by prices charged the housewife-will by prices charged the housewife-will
represent something like $\$ 147,000,000$. represent something like $\$ 147,000,000$.
Manifestly, there would be a great eco-
nomic gain, which would no doubt bring down the price of sugar, if these expensive factories could be operated throughout the entire year, with wider areas contributing
beets to each refinery. That is to say, beets to each refinery. That is to say,
instead of having rail transportation limited to a hundred miles, imagine the gain if the beets could be delivered from distances of four hundred miles at the same freight rate, and in such shape that when received at the preciation and utilized at any time, even months after their arrival. This is exactly what the new drying process makes possible. Fresh beets are prepared for the diffusion cells of the refinery by being cut into small pieces or slices which are technically known as cossettes. In this form, the pieces of the refinery and adjacent to lines of rail
transportation. At these dehydrating establishments the beets received from the nearby farmers are cut into cossettes and promptly desiccated-one short ton of dried, and the bulk being reduced propor tionately. Samples of beet cossettes treated
in this manner at a Bound Brook, New Jersey, factory have remained unimpaired in storage, just as raw sugar might be packed, for a period of more than two years. Measured by dry substance polarization, the percentage loss of cossettes stored in days, and curiously enough there was decrease of nearly fifty per cent of the because of the relatively low temperature employed, enzymic action is not halted by the dehydrating, and sugar production continues for a while, thus yielding an increase of from five to eight per cent over diffusion by the general practice. Thi increased sucrose production was discovered years ago by the Department of ulture, and was considered a puzzling phenomenon. Dehydrated cossettes now mally unformed sugars in the beets, and this gain alone is enough to reduce enormously the cost of running a refinery or to porting the dehydrated cossettes.
paration

Farmers now hundreds of miles away rom a refinery can grow beets and be sure a certain and profitable market; and the beets when dehydrated can be transporter in bulk, in box cars, without fear of deterioration. When received at the factory them freely and will remain fit for the diffusion process for many months. Not only that, but because of their relatively required to accomplish thorough extraction of the sucrose, the diffusion liquor will be icher, and to just this measure less heat operations.

A Curious Use for Aniline Dyes

D. ERWIN BAUMANn, a Koenigsberg (Prussia) surgeon, is using large quantities of aniline dyeing materials for
curative purposes and has successfully treated over 400 patients with this novel medicament. As a germ killer and arrester of noxious growths these materials are found to be far superior to any antiseptic substances so far known; they are quickly
distributed, do not coagulate albumen and distributed, do not coagulate albumen and, in the quantities used, are absolutely nonpoisonous. They can thus be used in a
very compact form, and their prompt destruction of all bacteria rapidly stops suppuration, heals wounded tissues, and beets can be permeated by the hot water for instance as in osteomyolitis, the period new system consists of drying plants lo- Also in ventrical ulcers, appendicitis, $\begin{aligned} & \text { cated at convenient points anywhere } \\ & \text { within a zone of four hundred miles from }\end{aligned}$ to be of great value; suppuration rapicis
to
RECENTLY PATENTEd INVENTIONS left, thus giving a signal to a following vehicle

ELECTRIC HORN CONTROL.-B F. Can. This , 827 5th St., Edmonton, Alberta, devices and particularly to a controlling device for electric horns, and provides an arrangement automobile in such a manner that the operating
auted to the steering ost an parts will be adjacent the hand at all times. VEHICLE SPRING.-L. E. MORROW, 812 ranklin St., Sandusky, Ohio. The invention provides a spring with equalizing levers, each and by a spring is connected to the body at the opposite side, so that when an end of the axle is raised at one side of the vehicle by contact of a
wheel mounted on the axle with an obtruction, it tends through certain means to draw the body down at the other side, which will side, which connects the body with a similar lever. The springs at one side of the vehicle body act on the springs at the other side to prevent tilting of the body.

TRACTOR DRIVE WHEEL.-A. R. TRACH, Lakefield. Minn. This invention provides a to an eccentrically mounted driving ring by a

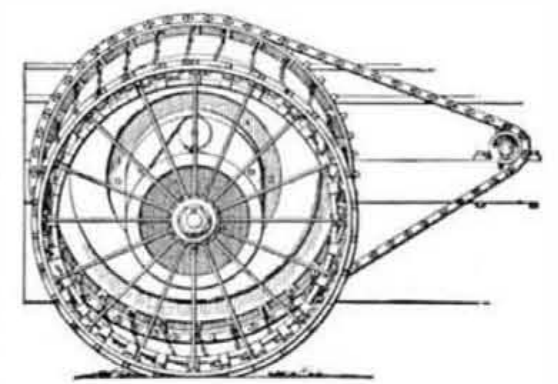

series of flexible members, the ring being mounted at such a point that the tractive power is exerted
on the wheel at the point where it will act to the on the wheel at the point where it will act to
best advantage to drive the tractor wheel.

TIRE.-J. J. Trotrer, 205 Kent St., Brooklyn, N. Y. This invention relates particularly to a
non-puncturable tire which gives substantially the same effect as the ordinary pneumatic tire
now commonly is use. It provides a resilient tire which does not depend upon air for giving the

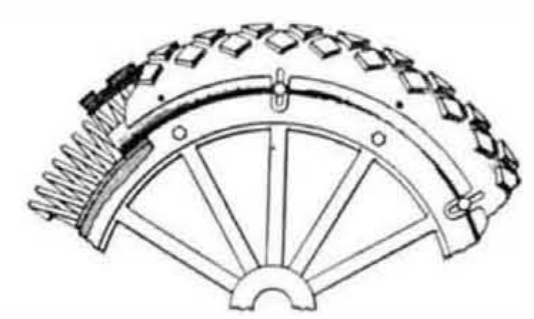

TIRE

cushtoning effect, and one whose spring and whing ordinary pneumatic tire now in use. The resiliency is produced by a

RHAUIZEN, 423 E. 77th St.. New York, N. Y. This invention improves the construction of a sprocket wheel
adapted for general utility and has particular reference to sprocket wheels for controlling the
movement of a moving picture film. In a film movement of a moving picture film. In a flim
sproket wheel great disadvantage has been and the invention provides a meens whereby the mechanism may be simplifed both in construction and manipulation, and whereby a worn sprocke may be replaced by a new one with a minimum expenditure of time and money.

AUXILIARY SEAT FOR AUTOMOBILES.W. H. Dovglas, 51 st St. and Broadway, New York, N. Y. This invention provides an auxiliary
seat arranged to permit convenient folding, when seat arranged to permit convenient folding, when
not in use, under the front seat, and to allow quick and safe extending for use without interfering and safe extending for use without interfering
with the comfort of the persons on the rear seat of the automobile and without interfering with the lowering of the windshield on the back of the front seat.

TIRE PROTECTOR.-A. W. NEFF, Bellevue Farm, Powell, Ohio. The improvement provides to prevent punctures and blowouts, to insur the desired cushioning effect with comparatively little air pressure in the tire, to reduce the tendency
to skid to a minimum, and to allow the use of a broad tread on a tire of small diameter.

\section{Designs}

DESIGN FOR A. SHOWER PLATE FOR GAS AND ELECTRIC FIXTURES.-S. Shapiro, 15 Laight St., New York, N. Y. The
top plan view shows this design of circular form. top plan view shows this design of circular form.
From the center spoke-like extensions radiate From the center spoke-like extensions radiate
to rings near the outer edge of the circle. Between these are added features that enrich the ornapresentations.

Nore.-Copies of any of these patents will bo cents each. Please state the name of patentee. 